Julia Hasslacher Georg Franz Lehner Ulrich Harler

Ronny Beer

Hanno Ulmer

Rudolf Kirchmair

Reiner Fischer-Colbrie

Romuald Bellmann

Stefan Dunzendorfer

Michael Joannidis

\section{Erratum to: Secretoneurin as a marker for hypoxic brain injury after cardiopulmonary resuscitation}

Published online: 19 September 2014

(C) Springer-Verlag Berlin Heidelberg and ESICM 2014

The online version of the original article can be found under doi:10.1007/s00134-014-3423-4.

J. Hasslacher · G. F. Lehner · U. Harler · R. Bellmann ·

S. Dunzendorfer · M. Joannidis ( $\bullet)$

Division of Intensive Care and Emergency Medicine, Department of Internal Medicine I, Medical University Innsbruck, Anichstr. 35, 6020 Innsbruck, Austria

e-mail: michael.joannidis@i-med.ac.at

Tel.: 0512-504-24180

R. Kirchmair

Department of Internal Medicine III, Medical University Innsbruck, Innsbruck, Austria

R. Fischer-Colbrie

Department of Pharmacology, Medical University Innsbruck, Innsbruck, Austria
R. Beer

Department of Neurology, Medical University Innsbruck, Innsbruck, Austria

H. Ulmer

Department of Medical Statistics, Informatics and Health Economics, Medical University Innsbruck, Innsbruck, Austria

\section{Erratum to: Intensive Care Med DOI 10.1007/s00134-014-3423-4}

Owing to oversights in typesetting, this article was published with errors in the legend of Fig. 1 and the column heads of Table 2 . These mistakes are rectified here. 


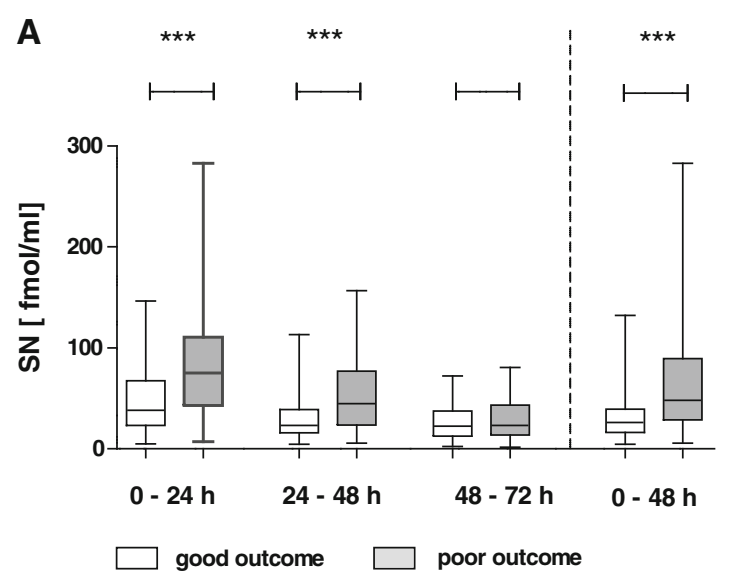

Fig. 1 a Secretoneurin (SN) serum levels of patients with good and poor outcome. SN levels [fmol/ml] in the first $72 \mathrm{~h}$ after CPR comparing patients with good and poor outcome; $n$ (total) $=134$; $n(0-24 \mathrm{~h})=111 ; n(24-48 \mathrm{~h})=98 ; n(48-72 \mathrm{~h})=77 ; n(0-48 \mathrm{~h})=$ 125. Graph shows median and range. $* * * p<0.001$. b Neuron-specific

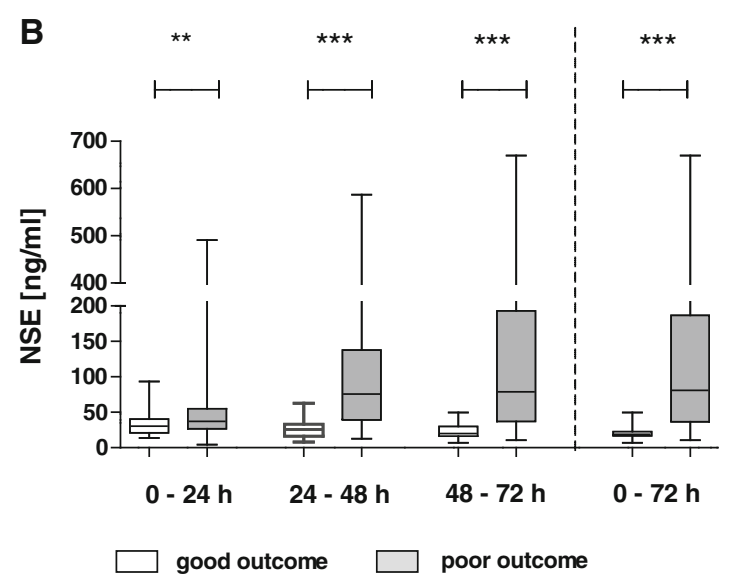

enolase (NSE) serum levels of patients with good and poor outcome. NSE levels [ng/ml] in the first $72 \mathrm{~h}$ after CPR comparing patients with good and poor outcome; $n$ (total) $=134 ; n \quad(0-24 \mathrm{~h})=119$; $n(24-48 \mathrm{~h})=87 ; n(48-72 \mathrm{~h})=57 ; n(0-72 \mathrm{~h})=128$. Graph shows median and range. $* * p<0.01, * * * p<0.001$

Table 2 Diagnostic accuracy of either SN or NSE at different time intervals to predict poor neurological outcome

\begin{tabular}{|c|c|c|c|c|c|c|}
\hline & Cut-off & AUC & Sens $(\%)$ & Spec $(\%)$ & PPV $(\%)$ & NPV $(\%)$ \\
\hline SN 0-24 h & $121 \mathrm{fmol} / \mathrm{mL}$ & $0.708[0.611-0.806]$ & 23 & 95 & 80 & 57 \\
\hline SN $24-48 \mathrm{~h}$ & $58 \mathrm{fmol} / \mathrm{mL}$ & $0.711[0.606-0.816]$ & 32 & 95 & 82 & 63 \\
\hline $\mathrm{SN} 48-72 \mathrm{~h}$ & $54 \mathrm{fmol} / \mathrm{mL}$ & $0.552[0.417-0.687]$ & 13 & 96 & 67 & 63 \\
\hline SN 0-48 h & $65 \mathrm{fmol} / \mathrm{mL}$ & $0.753[0.665-0.841]$ & 38 & 95 & 88 & 62 \\
\hline NSE $0-24 \mathrm{~h}$ & $33 \mathrm{ng} / \mathrm{mL}$ & $0.645[0.546-0.743]$ & 57 & 64 & 64 & 57 \\
\hline NSE 24-48 h & $33 \mathrm{ng} / \mathrm{mL}$ & $0.860[0.778-0.943]$ & 81 & 76 & 76 & 81 \\
\hline NSE $48-72 \mathrm{~h}$ & $33 \mathrm{ng} / \mathrm{mL}$ & 0.883 [0.787-0.979] & 83 & 84 & 83 & 82 \\
\hline NSE $0-72 \mathrm{~h}$ & $33 \mathrm{ng} / \mathrm{mL}$ & $0.881[0.815-0.946]$ & 80 & 81 & 80 & 79 \\
\hline
\end{tabular}

$A U C$ area under the curve, Sens sensitivity, Spec specificity, $P P V$ positive predictive value, $N P V$ negative predictive value, $S N$ secretoneurin, NSE neuron-specific enolase 